CLINICAL STUDY

\title{
Preterm birth does not affect bone mineral density in young adults
}

\author{
Petra E Breukhoven, Ralph W J Leunissen, Sandra W K de Kort, Ruben H Willemsen and Anita C S Hokken-Koelega \\ Subdivision of Endocrinology, Department of Pediatrics, Erasmus MC/Sophia Children's Hospital, Room number Sb-2603, Dr Molewaterplein 60, \\ 3015 GJ Rotterdam, The Netherlands \\ (Correspondence should be addressed to P E Breukhoven; Email: p.breukhoven@erasmusmc.nl)
}

\begin{abstract}
Objective: Previous studies showed conflicting data on the effect of prematurity on bone mineral density (BMD) in infants and children. Only a few studies investigated the long-term effects of prematurity on BMD in early adulthood. The objective of our study was to assess the long-term effects of preterm birth on $\mathrm{BMD}$ of the total body $\left(\mathrm{BMD}_{\mathrm{TB}}\right)$, lumbar spine $\left(\mathrm{BMD}_{\mathrm{LS}}\right)$ and bone mineral apparent density of the LS (BMAD $\mathrm{BS}_{\mathrm{LS}}$.

Design: Cross-sectional study.

Methods: It consists of two hundred and seventy-six healthy subjects without serious postnatal complications, aged 18-24 years. The contribution of gestational age to the variance in BMD in young adulthood and the differences in BMD between 151 subjects born preterm (median gestational age 32.2 weeks (interquartile range (IQR) 30.3-34.0)) and 125 subjects born at term (median gestational age 40.0 weeks (IQR 39.0-40.0)) were investigated. BMD was determined by dual-energy X-ray absorptiometry. Results: There were no significant linear correlations between gestational age and $\mathrm{BMD}_{\mathrm{TB}}(r=0.063$, $P=0.30), \mathrm{BMD}_{\mathrm{LS}}(r=0.062, P=0.31)$ and $\mathrm{BMAD}_{\mathrm{LS}}(r=0.069, P=0.26)$. Also after adjustment for possible confounders, gestational age was no significant contributor to the variance in $\mathrm{BMD}_{\mathrm{TB}}(P=0.27)$, $\operatorname{BMD}_{\mathrm{LS}}(P=0.91)$ and $\mathrm{BMAD}_{\mathrm{LS}}(P=0.87)$. No significant differences were found between preterm and term subjects with regard to $\mathrm{BMD}_{\mathrm{TB}}, \mathrm{BMD}_{\mathrm{LS}}$ and $\mathrm{BMAD}_{\mathrm{LS}}$.

Conclusion: In our cohort of 276 young adults, aged 18-24 years, gestational age was not a significant determinant in the variance of BMD. Preterm birth without serious postnatal complications is not associated with a lower BMD in young adulthood.
\end{abstract}

European Journal of Endocrinology 164 133-138

\section{Introduction}

Decreased mineralization of osteoid tissue during the early postnatal period is a known complication of very low birth weight and/or prematurely born infants (1-3). It comprises a variety of disturbances ranging from mild undermineralization to frank radiological rickets with fractures (4). Preterm infants are at an increased risk of low bone mineral density (BMD) as bone mineralization, along with calcium and phosphorus accretion, mainly occurs during the third trimester of pregnancy (5).

Previous studies showed conflicting data on the effect of preterm birth on BMD in infants and children. Prematurity, irrespective of birth weight, was found to be associated with lower BMD in infancy and early childhood (1, 6-9). In contrast, other studies in young children could not show differences in BMD due to prematurity $(2,10)$.

Owing to advances in neonatal care, survival of preterm and very low birth weight infants has significantly improved and an increasing number of these children reach adulthood. In 2007, the preterm birth rate in the United States was $12.7 \%$, which corresponds with $\sim 550.000$ preterm births per year (11). Moreover, this percentage is about $20 \%$ higher than the preterm birth rate in 1990 (11). It is, therefore, of increasing importance to assess the effect of prematurity on BMD in adulthood. Previous studies investigated the long-term effects of low birth weight and growth on BMD (12-20), but very few have studied the specific contribution of the duration of gestation on later $\operatorname{BMD}(14,21)$.

BMD in later life depends largely on the peak bone mass achieved in early adulthood and the subsequent bone loss (22). A high peak bone mass provides a larger reserve later in life $(22,23)$. Osteoporosis is an important and increasing cause of morbidity and mortality in the developed countries. It is characterized by low bone mass, deterioration of bone tissue and disruption of bone architecture, compromised bone strength and an increase in the risk of fracture (24). According to the 
WHO diagnostic classification, osteoporosis is defined by BMD at the hip or spine that is $\leq 2.5$ SDS below the young normal mean reference population (24). Since early prevention of osteoporosis is likely to be more successful than treatment of an already established disorder, it is essential to identify potential risk factors.

We hypothesized that prematurity is associated with lower BMD in early adulthood. Therefore, the aim of our study was to assess the long-term effects of gestational age and particularly preterm birth on BMD in a large group of young adults.

\section{Subjects and methods}

\section{Subjects}

This study investigated a cohort of 276 healthy subjects, aged 18-24 years. Subjects born preterm (gestational age $<36$ weeks, $n=151$ ) had been admitted to the neonatal intensive care unit of the Erasmus University Medical Centre shortly after birth. In total, $37.7 \%$ of all preterm subjects were born small for gestational age. Term controls of similar age (gestational age $\geq 36$ weeks, $n=125$ ) were randomly asked to participate from different educational institutes.

All subjects fulfilled the same inclusion criteria: i) age 18-24 years, ii) adult pubertal stage, iii) Caucasian, iv) born singleton, v) a neonatal period without signs of severe asphyxia (defined as an Apgar score below 3 after $5 \mathrm{~min}$ ) or long-term complications of respiratory ventilation, such as bronchopulmonary dysplasia, vi) maximum duration of respiratory ventilation and/or oxygen supply of 2 weeks in the neonatal period. Subjects with a serious neonatal complication (e.g. necrotizing enterocolitis, degree 3 or more intraventricular haemorrhage, spastic hemiplegia or quadriplegia), an endocrine or metabolic disorder, chromosomal defects, syndromes or dysmorphic symptoms suggestive for a yet unknown syndrome were excluded. Subjects with a condition known to interfere with growth, including GH deficiency, severe chronic illness, emotional deprivation, GH treatment, glucocorticosteroid treatment and radiotherapy were also excluded. Birth data were taken from hospital records, and records from community health services and general practitioners.

The Medical Research Ethics Committee of Erasmus University Medical Centre, Rotterdam, The Netherlands, approved this study. Written informed consent was obtained from all the participants.

\section{Methods}

Anthropometry Adult height was measured in the upright position to the nearest $0.1 \mathrm{~cm}$ using a Harpenden stadiometer (Holtain Ltd, Crymmyth, UK). Weight was measured to the nearest $0.1 \mathrm{~kg}$ on a digital scale (Servo Balance KA-20-150S). All anthropometric measurements were performed twice, and the mean value was used for analysis.

Bone mineral density Bone mass of the total body (TB), lumbar spine (LS), lean body mass (LBM) and fat mass (FM) were measured by dual-energy X-ray absorptiometry (DXA, type Lunar-Prodigy, GE Healthcare, Chalfont St Giles, UK). All scans were made on the same machine, and quality assurance was performed daily. The coefficient of variation (CV) was $0.5 \%$ for total body BMD and $1.0 \%$ for spine BMD (25-27). The CV for lean mass and FM has been reported to be 0.7 and $1.2 \%$ respectively $(25,26)$.

To adjust for differences in bone size, we calculated bone mineral apparent density of the $\mathrm{LS}\left(\mathrm{BMAD}_{\mathrm{LS}}\right)\left(\mathrm{g} / \mathrm{cm}^{3}\right)$ with the model $\mathrm{BMAD}_{\mathrm{LS}}=\mathrm{BMD}_{\mathrm{LS}} \times(4 /(\pi \times$ width $))(28)$. Width was the mean width of the second to fourth lumbar vertebral body. This model was validated by in vivo volumetric data obtained from magnetic resonance imaging of the lumbar vertebrae.

Questionnaire All subjects completed a structured questionnaire, which included questions on socioeconomic status of the participants and their parents, cigarette smoking, alcohol consumption and usage of oral contraceptives. Socioeconomic status was determined by using educational level of the participant, which was assessed by the highest grade of school completed or currently participating in, and categorized into i) high (higher general secondary education or higher), ii) median (junior general secondary education secondary vocational education) and iii) low education (preparatory middle-level vocational education or lower).

\section{Statistical analysis}

Clinical characteristics are expressed as median (interquartile range). Birth weight and length were adjusted for gestational age and gender (29), and baseline data in young adulthood were adjusted for age and gender (30). BMD data are expressed as mean (s.D.). SDSs for $\mathrm{BMD}_{\mathrm{TB}}, \mathrm{BMD}_{\mathrm{LS}}$ and $\mathrm{BMAD}_{\mathrm{LS}}$ were calculated using reference data of Boot et al. (31).

Independent samples $t$-tests were used to evaluate differences in clinical characteristics between preterm and term subjects. To test for linear relationships between gestational age and $\mathrm{BMD}_{\mathrm{TB}}, \mathrm{BMD}_{\mathrm{LS}}$ and $\mathrm{BMAD}_{\mathrm{LS}}$, Pearson's correlation coefficient was used. The longterm effect of gestational age on $\mathrm{BMD}_{\mathrm{TB}}, \mathrm{BMD}_{\mathrm{LS}}$ and $\mathrm{BMAD}_{\mathrm{LS}}$ in young adulthood was analysed using multiple regression analyses, corrected for possible confounders (gender, age, birth weight SDS, birth length SDS, adult height SDS, LBM and FM). The interaction term birth length SDS $\times$ adult height SDS was added to the multiple regression model to ensure that the effect of these variables was modelled correctly. 
To determine differences between preterm and term subjects with regard to BMD, multiple regression analysis was used with correction for age and gender and subsequently also with correction for gender, age, birth weight SDS, birth length SDS, adult height SDS, LBM and FM.

Results were regarded statistically significant at $P<0.05$. Statistics were performed using the computer Statistical Package for Social Science (SPSS version 16.0; SPSS, Inc., Chicago, IL, USA).

\section{Results}

\section{Clinical characteristics}

Table 1 shows the baseline characteristics of the study group. The total group of 276 subjects had a median age of 20.9 years. Besides the obvious difference in gestational age, preterm subjects had a lower birth length SDS than term subjects.

\section{BMD and gestational age}

There were no significant linear correlations between gestational age and $\mathrm{BMD}_{\mathrm{TB}}(r=0.063, P=0.30)$, $\mathrm{BMD}_{\mathrm{LS}}(r=0.062, P=0.31)$ and $\mathrm{BMAD}_{\mathrm{LS}}(r=0.069$, $P=0.26)$. Multiple regression analyses showed that gestational age was not a significant contributor to the variance in $\mathrm{BMD}_{\mathrm{TB}}\left(P=0.27, R^{2}=0.370\right), \mathrm{BMD}_{\mathrm{LS}}$ $\left(P=0.91, \quad R^{2}=0.165\right) \quad$ and $\quad \mathrm{BMAD}_{\mathrm{LS}} \quad(P=0.87$, $\left.R^{2}=0.262\right)$, after adjustment for age, gender, birth weight SDS, birth length SDS, adult height SDS, LBM and FM as additional independent variables.

Furthermore, SDSs of BMD of the LS were not significantly correlated with gestational age $\left(\mathrm{BMD}_{\mathrm{LS}}\right.$ SDS: $r=0.069, P=0.254$ and BMAD $\mathrm{LS}_{\mathrm{S}}$ SDS: $r=0.031$, $P=0.605)$, whereas $\mathrm{BMD}_{\mathrm{TB}}$ SDS was significantly correlated with gestational age $(r=0.137, P=0.023)$. However, after adjustments for possible confounders, this correlation disappeared $\left(\mathrm{BMD}_{\mathrm{TB}}\right.$ SDS $(P=0.28$, $\left.R^{2}=0.290\right), \mathrm{BMD}_{\mathrm{LS}} \operatorname{SDS}\left(P=0.941, R^{2}=0.175\right)$ and $\left.\mathrm{BMAD}_{\mathrm{LS}} \operatorname{SDS}\left(P=0.815, R^{2}=0.064\right)\right)$.

Further analysis showed that adult weight, specified as LBM and TB FM, was an important determinant of BMD in young adulthood, regardless of size at birth and gestational age. LBM was significantly associated with $\mathrm{BMD}_{\mathrm{TB}}(\beta=0.007, P<0.001)$ and $\mathrm{BMD}_{\mathrm{LS}}(\beta=0.008$, $P<0.001)$. FM was also associated with $\mathrm{BMD}_{\mathrm{TB}}$ $(\beta=0.002, P<0.001)$ and $\mathrm{BMD}_{\mathrm{LS}}(\beta=0.002, P=0.08)$.

In addition, we evaluated the possible confounding effects of socioeconomic status, smoking, alcohol and the usage of oral contraceptives on these associations. The socioeconomic status was low in $8.8 \%$, median in $22.6 \%$ and high in $68.8 \%$ of all subjects, and $22.8 \%$ of all subjects smoked. Of all subjects reporting alcohol consumption (80.8\%), 28.6\% had an alcohol consumption $\geq 5$ units/week. None of these factors had a significant influence on the BMD (TB and LS) outcomes.

\section{BMD in preterm versus term subjects}

No significant differences were found between preterm and term subjects with regard to $\mathrm{BMD}_{\mathrm{TB}}, \mathrm{BMD}_{\mathrm{LS}}$ and $\mathrm{BMAD}_{\mathrm{LS}}$ after correction for age and gender (Table 2). Even after additional adjustment for significant independent variables like birth length SDS, adult height SDS, birth weight SDS, LBM and FM, BMD outcomes did not significantly differ between preterm and term subjects.

\section{Discussion}

Our study in 276 young adults showed that gestational age was not a significant contributor to the variance in $\mathrm{BMD}\left(\mathrm{BMD}_{\mathrm{TB}}\right.$ and $\left.\mathrm{BMD}_{\mathrm{LS}}\right)$ and $\mathrm{BMAD}\left(\mathrm{BMAD}_{\mathrm{LS}}\right)$ in young adulthood. In addition, our subgroup analysis did not show differences between subjects born preterm or term. Thus, in contrast to our hypothesis, preterm birth was not associated with lower BMD in early adulthood.

Peak bone mass is an important determinant of BMD in later life, but the exact age at which peak bone mass is reached is not well established. Recent data show that peak bone mass is probably attained by the mid-twenties (32). We are one of the first to investigate BMD in subjects born preterm at a mean age of 21 years, thus around the age of reaching peak bone mass. Our results are, therefore, important for the evaluation of the longterm consequences of preterm birth.

Our subgroup analysis showed no differences in BMD between subjects born preterm or term. Dalziel et al.

Table 1 Clinical characteristics. All values are given as median (interquartile range).

\begin{tabular}{lccc}
\hline & Total group & Preterm & Term \\
\hline$n$ & 276 & 151 & 125 \\
Gender (M/F) & $119 / 157$ & $76 / 75$ & $43 / 82$ \\
Gestational age (weeks) & $34.9(32.0$ to 40.0$)$ & $32.2(30.3 \text { to } 34.0)^{*}$ & $40.0(39.0$ to 40.0$)$ \\
Birth length SDS & $-0.6(-1.7$ to 0.3$)$ & $-1.1(-2.8 \text { to } 0.3)^{*}$ & $-0.4(-1.3$ to 0.2$)$ \\
Birth weight SDS & $-0.3(-1.6$ to 0.6$)$ & $-0.3(-2.1$ to 0.8$)$ & $-0.3(-1.2$ to 0.4$)$ \\
Age (years) & $20.9(19.6$ to 22.3$)$ & $21.0(19.7$ to 22.3$)$ & $20.6(19.4$ to 22.4$)$ \\
Adult height SDS & $-0.3(-1.2$ to 0.3$)$ & $-0.3(-1.1$ to 0.2$)$ & $-0.4(-1.5$ to 0.5$)$ \\
Adult weight SDS & $-0.3(-1.0$ to 0.3$)$ & $-0.2(-0.9$ to 0.4$)$ & $-0.4(-1.0$ to 0.3$)$ \\
\hline
\end{tabular}

${ }^{\star} P<0.001$ between preterm and term. 
Table 2 Bone mineral density in young adults born preterm vs term. All values are given as mean (SDS).

\begin{tabular}{|c|c|c|c|c|c|}
\hline & Total group $(n=276)$ & Preterm $(n=151)$ & Term $(n=125)$ & $P$ value* & $\boldsymbol{P}$ value $^{\dagger}$ \\
\hline \multicolumn{6}{|l|}{ Total body } \\
\hline $\mathrm{BMD}_{\text {TВ }}\left(\mathrm{g} / \mathrm{cm}^{2}\right)$ & $1.17(0.09)$ & $1.17(0.08)$ & $1.18(0.10)$ & 0.127 & 0.429 \\
\hline $\mathrm{BMD}_{\text {TB }}$ SDS & $-0.50(0.87)$ & $-0.59(0.83)$ & $-0.40(0.91)$ & 0.184 & 0.534 \\
\hline \multicolumn{6}{|l|}{ Lumbar spine } \\
\hline $\mathrm{BMD}_{\mathrm{LS}}\left(\mathrm{g} / \mathrm{cm}^{2}\right)$ & $1.20(0.13)$ & $1.20(0.13)$ & $1.21(0.13)$ & 0.462 & 0.878 \\
\hline$B M D_{L S}$ SDS & $-0.45(0.80)$ & $-0.49(0.82)$ & $-0.39(0.78)$ & 0.467 & 0.997 \\
\hline $\operatorname{BMAD}_{\mathrm{LS}}\left(\mathrm{g} / \mathrm{cm}^{3}\right)$ & $0.37(0.04)$ & $0.37(0.05)$ & $0.37(0.04)$ & 0.918 & 0.751 \\
\hline BMAD $_{\text {LS }}$ SDS & $-0.52(0.93)$ & $-0.55(0.99)$ & $-0.49(0.84)$ & 0.879 & 0.651 \\
\hline
\end{tabular}

${ }^{*}$ Preterm vs term; $P$ values are given after correction for age and gender. ${ }^{\dagger}$ Preterm vs term; $P$ values are given after correction for age, gender, birth length SDS, adult height SDS, birth weight SDS, LBM and fat mass.

investigated a cohort of 174 adults (mean age 31 years) whose mothers had participated in a randomized trial of antenatal betamethasone treatment. Although the main aim of the study was to determine the effect of maternal betamethasone usage on later BMD, they also showed that prematurity had no effect on peak bone mass (21). Hamed et al. showed that, in a cohort of 230 women (aged 20-23 years), BMD was not influenced by prematurity (14), although in that study no adjustments for possible confounders (e.g. LBM, FM or weight) were made and the cohort consisted of female subjects only.

Weiler et al. (33) showed that preterm born adolescents had a lower bone mineral content (BMC) than those born at term. However, after correction for adult height and weight, these differences disappeared, indicating that the effect of gestational age on BMC was largely influenced by adult body size.

Previous studies in infancy and early childhood showed differences in BMD between preterm and term subjects $(1,6,7,9)$, but we could not confirm such results in our young adults. One explanation might be that there was a catch-up in bone mineralization during infancy and childhood (34), but to prove this hypothesis, prospective longitudinal research in preterm and term subjects is mandatory.

A relative high percentage of our premature study population consisted of subjects born small for gestational age (SGA; 37.7\%), compared to the normal population in which the prevalence of SGA is only $2.3 \%$. In clinical practice, the majority of children born SGA are born preterm. Furthermore, our study comprises a relatively healthy population. Subjects with, for example, a complicated neonatal period were excluded from our analysis, and it might be that such subjects have a higher risk of lower BMD.

BMD was assessed for TB and LS. As there are differences in cell biology between these two sites $(35,36)$, gestational age and/or prematurity could have different effects on $\mathrm{BMD}_{\mathrm{TB}}$ and $\mathrm{BMD}_{\mathrm{LS}}$. Despite these differences, gestational age was no significant determinant of both $\mathrm{BMD}_{\mathrm{TB}}$ and $\mathrm{BMD}_{\mathrm{LS}}$. Furthermore, it is important to realize that bone density is just one aspect of bone quality, as bones are complex three-dimensional structures (37).

Analysis of BMD showed that prematurity and also birth size had no long-term consequences on BMD. Instead, adult weight, LBM and TB FM were important determinants of BMD in young adulthood. So it seems important to ensure that appropriate growth and nutrition are maintained throughout childhood and adolescence. Although our data are reassuring, there is no guarantee that BMD will remain normal when subjects become older. Longer term follow-up is, therefore, still warranted.

DXA was used to assess BMD, as it is the most commonly used technique for BMD assessment because of low radiation exposure, great precision and accuracy, and short scanning time (6-10 min). Additionally, DXA performs whole body rather than slice measurements (CT) $(31,38)$. A shortcoming of DXA is that it measures bone in two dimensions providing only an estimation of bone density. BMD is obtained by dividing BMC (g) by the projected bone image (area in $\mathrm{cm}^{2}$ ). BMD is, therefore, dependent on bone size, and this might lead to erroneous interpretations of BMD values. A widely used and validated model to correct for bone size is BMAD (volumetric BMD) $(22,28,39)$. For that reason, we added $\mathrm{BMAD}_{\mathrm{LS}}$ as one of the parameters reflecting bone mineralization.

\section{Conclusions}

In conclusion, in a cohort of 276 young adults, gestational age was not a significant determinant in the variance of BMD (TB and LS). BMD was not adversely affected in young adults born moderately preterm. Thus, in contrast to our hypothesis, preterm birth without postnatal complications is not associated with a lower BMD in young adulthood. These findings are of major importance as an increasing number of preterm born subjects reach adulthood.

\section{Declaration of interest}

The authors declare that there is no conflict of interest that could be perceived as prejudicing the impartiality of the research reported. 


\section{Funding}

The study was financially supported by Netherlands Organisation for Scientific Research (NWO) (ACSHK received the ASPASIA award (grant number 015000 088)), and by grants from Revolving Fund 2001, Vereniging Trustfonds, Erasmus University Rotterdam, the Jan Dekkerstichting/Dr Ludgardine Bouwmanstichting, Stichting De Drie Lichten, The Netherlands, and an investigator-initiated research grant provided by Pfizer, Inc., USA.

\section{Acknowledgements}

We would like to thank all participants. We greatly acknowledge Mrs J Dunk, Mrs M Huibregtse-Schouten and Mrs I van Slobbe, research nurses, and M Eshuis, A Hellingsman, L Holl, C Nederstigt, P Oosterbeek, S Rambaran and N Verbeet, research nurses, for their technical assistance and support with data collection. We acknowledge the Erasmus University MC Rotterdam, Maasstad Hospital Rotterdam, University MC Nijmegen, Catharina Hospital Eindhoven, Leiden University MC, Juliana Children's Hospital, the Hague, and University Medical Centre Groningen. We thank J P Sluimer and P Kooy of the Department of Nuclear Medicine, Erasmus University MC.

\section{References}

1 Kurl S, Heinonen K \& Lansimies E. Effects of prematurity, intrauterine growth status, and early dexamethasone treatment on postnatal bone mineralisation. Archives of Disease in Childhood. Fetal and Neonatal Edition 200083 F109-F111. (doi:10.1136/fn.83.2.F109)

2 Kurl S, Heinonen K, Lansimies E \& Launiala K. Determinants of bone mineral density in prematurely born children aged 6-7 years. Acta Paediatrica $1998 \mathbf{8 7}$ 650-653. (doi:10.1080/080352 598750014067)

3 Abrams SA. In utero physiology: role in nutrient delivery and fetal development for calcium, phosphorus, and vitamin D. American Journal of Clinical Nutrition $2007 \mathbf{8 5}$ 604S-607S.

4 Rohana J. Hasmawati J \& Zulkifli SZ. Risk factors associated with low bone mineral content in very low birth weight infants. Singapore Medical Journal 200748 191-194.

5 Taeusch W \& Ballard R. Avery's Disease of the Newborn London: WB Saunders Company, 1998.

6 Abou Samra H, Stevens D, Binkley T \& Specker B. Determinants of bone mass and size in 7-year-old former term, late-preterm, and preterm boys. Osteoporosis International 200920 1903-1910. (doi:10.1007/s00198-009-0896-z)

7 Bowden LS, Jones CJ \& Ryan SW. Bone mineralisation in ex-preterm infants aged 8 years. European Journal of Pediatrics 1999158 658-661. (doi:10.1007/s004310051171)

8 Chan GM, Armstrong C, Moyer-Mileur L \& Hoff C. Growth and bone mineralization in children born prematurely. Journal of Perinatology 200828 619-623. (doi:10.1038/jp.2008.59)

9 Ahmad I, Nemet D, Eliakim A, Koeppel R, Grochow D, Coussens M, Gallitto S, Rich J, Pontello A, Leu SY, Cooper DM \& Waffarn F. Body composition and its components in preterm and term newborns: a cross-sectional, multimodal investigation. American Journal of Human Biology 201022 69-75. (doi:10.1002/ajhb.20955)

10 Fewtrell MS, Prentice A, Jones SC, Bishop NJ, Stirling D, Buffenstein R, Lunt M, Cole TJ \& Lucas A. Bone mineralization and turnover in preterm infants at 8-12 years of age: the effect of early diet. Journal of Bone and Mineral Research 199914 810-820. (doi:10.1359/jbmr.1999.14.5.810)

11 Hamilton BE, Martin JA \& Ventura SJ. Births: Preliminary Data for 2007. National Vital Statistics Reports 200957 1-23.

12 Oliver H, Jameson KA, Sayer AA, Cooper C \& Dennison EM, Hertfordshire Cohort Study G. Growth in early life predicts bone strength in late adulthood: the Hertfordshire Cohort Study. Bone 200741 400-405. (doi:10.1016/j.bone.2007.05.007)
13 Leunissen RW, Stijnen T, Boot AM \& Hokken-Koelega AC. Influence of birth size and body composition on bone mineral density in early adulthood. The PROGRAM-study. Clinical Endocrinology 200869 386-392. (doi:10.1111/j.1365-2265.2008.03226.x)

14 Hamed HM, Purdie DW, Ramsden CS, Carmichael B, Steel SA \& Howey S. Influence of birth weight on adult bone mineral density. Osteoporosis International 19933 1-2. (doi:10.1007/BF01623168)

15 te Velde SJ, Twisk JW, van Mechelen W \& Kemper HC. Birth weight and musculoskeletal health in 36-year-old men and women: results from the Amsterdam Growth and Health Longitudinal Study. Osteoporosis International 200415 382-388. (doi:10. 1007/s00198-003-1554-5)

16 Antoniades L, MacGregor AJ, Andrew T \& Spector TD. Association of birth weight with osteoporosis and osteoarthritis in adult twins. Rheumatology 200342 791-796. (doi:10.1093/rheumatology/ keg227)

17 Javaid MK, Lekamwasam S, Clark J, Dennison EM, Syddall HE, Loveridge N, Reeve J, Beck TJ \& Cooper C, Hertfordshire Cohort Study G. Infant growth influences proximal femoral geometry in adulthood. Journal of Bone and Mineral Research 200621 508-512. (doi:10.1359/jbmr.051214)

18 Cooper C, Fall C, Egger P, Hobbs R, Eastell R \& Barker D. Growth in infancy and bone mass in later life. Annals of the Rheumatic Diseases 199756 17-21. (doi:10.1136/ard.56.1.17)

19 Yarbrough DE, Barrett-Connor E \& Morton DJ. Birth weight as a predictor of adult bone mass in postmenopausal women: the Rancho Bernardo Study. Osteoporosis International 200011 626-630. (doi:10.1007/s001980070085)

20 Hovi P, Andersson S, Jarvenpaa AL, Eriksson JG, StrangKarlsson S, Kajantie E \& Makitie O. Decreased bone mineral density in adults born with very low birth weight: a cohort study. PLoS Medicine 20096 e1000135. (doi:10.1371/journal.pmed. 1000135)

21 Dalziel SR, Fenwick S, Cundy T, Parag V, Beck TJ, Rodgers A \& Harding JE. Peak bone mass after exposure to antenatal betamethasone and prematurity: follow-up of a randomized controlled trial. Journal of Bone and Mineral Research 200621 1175-1186. (doi:10.1359/jbmr.060516)

22 van der Sluis IM, de Ridder MA, Boot AM, Krenning EP \& de Muinck Keizer-Schrama SM. Reference data for bone density and body composition measured with dual energy $\mathrm{X}$ ray absorptiometry in white children and young adults. Archives of Disease in Childhood 200287 341-347. (doi:10.1136/adc.87.4. 341)

23 Ribot C, Tremollieres F \& Pouilles JM. Late consequences of a low peak bone mass. Acta Paediatrica. Supplementum 1995411 31-35. (doi:10.1111/j.1651-2227.1995.tb13857.x)

24 National Osteoporosis Foundation. Clinician's Guide to Prevention and Treatment of Osteoporosis. Washington, DC: National Osteoporosis Foundation, 2010.

25 Bonnick SL, Johnston CC Jr, Kleerekoper M, Lindsay R, Miller P, Sherwood L \& Siris E. Importance of precision in bone density measurements. Journal of Clinical Densitometry 20014 105-110. (doi:10.1385/JCD:4:2:105)

26 Kiebzak GM, Leamy LJ, Pierson LM, Nord RH \& Zhang ZY. Measurement precision of body composition variables using the lunar DPX-L densitometer. Journal of Clinical Densitometry 20003 35-41. (doi:10.1385/JCD:3:1:035)

27 Shepherd JA, Fan B, Lu Y, Lewiecki EM, Miller P \& Genant HK. Comparison of BMD precision for Prodigy and Delphi spine and femur scans. Osteoporosis International 200617 1303-1308. (doi:10.1007/s00198-006-0127-9)

28 Kroger H, Vainio P, Nieminen J \& Kotaniemi A. Comparison of different models for interpreting bone mineral density measurements using DXA and MRI technology. Bone 199517 157-159. (doi:10.1016/S8756-3282(95)00162-X)

29 Usher R \& McLean F. Intrauterine growth of live-born Caucasian infants at sea level: standards obtained from measurements in 7 dimensions of infants born between 25 and 44 weeks of gestation. Journal of Pediatrics $1969 \mathbf{7 4}$ 901-910. (doi:10.1016/S00223476(69)80224-6) 
30 Fredriks AM, van Buuren S, Burgmeijer RJ, Meulmeester JF, Beuker RJ, Brugman E, Roede MJ, Verloove-Vanhorick SP \& Wit JM. Continuing positive secular growth change in The Netherlands 1955-1997. Pediatric Research 200047 316-323. (doi:10.1203/00006450-200003000-00006)

31 Boot AM, de Ridder MA, Pols HA, Krenning EP \& de Muinck Keizer-Schrama SM. Bone mineral density in children and adolescents: relation to puberty, calcium intake, and physical activity. Journal of Clinical Endocrinology and Metabolism 199782 57-62. (doi:10.1210/jc.82.1.57)

32 Walsh JS, Henry YM, Fatayerji D \& Eastell R. Lumbar spine peak bone mass and bone turnover in men and women: a longitudinal study. Osteoporosis International 200920 355-362. (doi:10.1007/ s00198-008-0672-5)

33 Weiler HA, Yuen CK \& Seshia MM. Growth and bone mineralization of young adults weighing less than $1500 \mathrm{~g}$ at birth. Early Human Development 200267 101-112. (doi:10. 1016/S0378-3782(02)00003-8)

34 Cooke RJ, Rawlings DJ, McCormick K, Griffin IJ, Faulkner K, Wells JC, Smith JS \& Robinson SJ. Body composition of preterm infants during infancy. Archives of Disease in Childhood. Fetal and Neonatal Edition 199980 F188-F191. (doi:10.1136/fn. 80.2.F115)
35 Martin TJ, Ng KW \& Nicholson GC. Cell biology of bone. Bailliere's Clinical Endocrinology and Metabolism 19882 1-29. (doi:10.1016/ S0950-351X(88)80006-5)

36 Rocher E, Chappard C, Jaffre C, Benhamou CL \& Courteix D. Bone mineral density in prepubertal obese and control children: relation to body weight, lean mass, and fat mass. Journal of Bone and Mineral Metabolism 200826 73-78. (doi:10.1007/s00774-007-0786-4)

37 Rauch F \& Schoenau E. Skeletal development in premature infants: a review of bone physiology beyond nutritional aspects. Archives of Disease in Childhood. Fetal and Neonatal Edition 200286 F82-F85. (doi:10.1136/fn.86.2.F82)

38 Rigo J, de Curtis M \& Pieltain C. Nutritional assessment in preterm infants with special reference to body composition. Seminars in Neonatology 20016 383-391. (doi:10.1053/siny.2001.0073)

39 Boot AM, Engels MA, Boerma GJ, Krenning EP \& De Muinck KeizerSchrama SM. Changes in bone mineral density, body composition, and lipid metabolism during growth hormone $(\mathrm{GH})$ treatment in children with GH deficiency. Journal of Clinical Endocrinology and Metabolism 199782 2423-2428. (doi:10.1210/jc.82.8.2423)

Received 3 October 2010

Accepted 28 October 2010 